\title{
Effect of TSS Removal from Stormwater by Mixed Media Column on T-N, T-P, and Organic Material Removal
}

\author{
Hoi Jin Kim ${ }^{1}$, Jae-Woo Choi ${ }^{2}$, Tae-Han Kim ${ }^{3}$, Jong-Sup Park ${ }^{1}$ and Byungryul An ${ }^{1, *}$ (i) \\ 1 Department of Civil Engineering, Sangmyung University, Cheonan, Chungnam 31066, Korea; \\ lalala1968@naver.com (H.J.K.); jonpark@smu.ac.kr (J.-S.P.) \\ 2 Center for Water Resource Cycle Research, Korea Institute of Science and Technology, Hwarangno 14-gil 5, \\ Seongbuk-gu, Seoul 02792, Korea; plead36@kist.re.kr \\ 3 Department of Environmental and Landscaping, Sangmyung University, Cheonan, Chungnam 31066, Korea; \\ aehankim@smu.ac.kr \\ * Correspondence: bran@smu.ac.kr; Tel.: +82-41-550-5497
}

Received: 16 July 2018; Accepted: 9 August 2018; Published: 10 August 2018

\begin{abstract}
The water quality of a waterbody influenced by stormwater runoff was tested in a lab-scale setting by filtration. The filtration bed was packed with two or three types of media, sand, bottom ash (BA), and woodchips (WC), and tested with three hydraulic conductivities (HCs). Five pollutants-namely, total suspended solids (TSS): BOD, COD, T-N, and T-P, were analyzed and compared. The application of sand-bottom ash (S-BA) and bottom ash-sand (BA-S) media types showed the highest removal efficiencies for TSS, BOD, COD, T-N, and T-P, respectively. Among the five pollutants, TSS achieved the highest removal efficiency for any of the filter media, which was up to $93 \%$ for the S-BA and decreased to $72 \%$ with an increase in $\mathrm{HC}$, followed by T-P > BOD $>$ COD $=\mathrm{T}-\mathrm{N}$. The maximum removal efficiency values of BOD and COD were obtained at $67 \%$ and $52 \%$, respectively, indicating that BOD removal was always higher than COD removal. Due to the low $\mathrm{C}: \mathrm{N}$ and high $\mathrm{HC}$, biodegradation was disregarded during filtration. Based on the different removal forms of T-P compared with TSS, adsorption would be involved in the removal of dissolved T-P by BA.
\end{abstract}

Keywords: water quality; pollution; stormwater; sorption

\section{Introduction}

To improve or maintain water quality in waterbodies, several pollutants, such as sediments, organic materials, and nutrients from point sources (PSs) including domestic or industrial wastewater, as well as from nonpoint sources (NPSs), such as stormwater runoff, need to be addressed. Previous research estimating the contribution of point and nonpoint source pollution concluded that nitrogen and phosphorus from nonpoint input, such as agriculture, urban activity, and industry to surface water were dominant in stormwater discharge, at $82 \%$ and $84 \%$, respectively [1,2].

Whilst awareness around the influence which stormwater runoff has on water quality is increasing, regulations to control pollutants from NPSs have been established and implemented. In the U.S., a total maximum daily load (TMDL) for each pollutant was set per year by the federal Clean Water Act (CWA) [3], and in Korea, the total water pollution load management system (TPLMS) was first introduced in 1998. At first, the TPLMS included only a biochemical oxygen demand (BOD) parameter for organic carbon, but was then enhanced by adding T-P to the contaminant list in 2011 [4].

Horner et al. [5] suggested that potentially harmful pollutants from urban runoff to receiving waters included solid, oxygen-demanding substances; nitrogen and phosphorus; pathogens; petroleum hydrocarbons; and metals and synthetic organics. Sediments causing suspended solids (SS) and 
turbidity are considered to be the most common contaminants that originate from various sources and processes, such as the erosion of pervious surfaces, erosion at construction sites, and deposited particles. Elevated levels of sediment transferred by runoff affect the biological diversity of water bodies, because increased levels of sediment inhibit the penetration of sunlight [6]. The presence of organic carbon in a water body depletes the dissolved oxygen (DO), which can result in complex issues, such as changes to color, taste, and odor, as well as increases in coagulant and disinfectant doses in drinking water treatments [7]. Nitrogen and phosphorus are considered to be nutrients that cause eutrophication of water bodies, and both nutrients have been very carefully monitored and controlled in surface waters in Korea since the beginning of a restoration project for 4 major rivers [8]. There are some processes designed to remove nitrogen and phosphorus, such as nitrification and denitrification, adsorption, and coagulation. However, the suggested methods are usually carried out for point source pollution, and they have been restricted for non-point source pollution treatment due to unexpected influent volumes and rainfall events.

Many stormwater treatment technologies have been utilized to reduce peak runoff volume and to remove contaminants. Wetlands, sedimentation ponds, filtration systems, and infiltration systems have been introduced. Among these technologies, filtration systems play an important role in controlling water pollutants by passing polluted water through gravel, sand, or soil [9]. Filtration removal efficiency and volumes treated depend on particle size, with respect to the physical condition of the filtration media [10]. Filtration media can become chemically incorporated with organic, inorganic, and toxic constituents by factors such as sorption, precipitation, and binding [11]. Furthermore, sand filtration biologically removes specific organic pollutants by biodegradation, and nitrogen by biological infiltrations [12,13].

Replacing sand with other reusable materials from waste has been attempted, and the reuse of bottom ash (BA), which is a thermal power plant waste, was demonstrated to be a cost-effective adsorbent used to remove toxic pollutants during water treatment. Lin and Yang [14] observed that the use of coal bottom ash had 95\% and 35\% removal efficiencies for copper and COD, respectively. Fly ash was also applied for seven years of field operation by Oklahoma State University, and the authors found that the Bioretention cells (BRC) with $5 \%$ fly ash reduced $68-75 \%$ phosphorus concentration from stormwater. [15]. Other attempts carried out by Gupta et al. [16] achieved 100\% removal efficiency for a water-soluble dye, namely, halogen-containing fluorescein. The use of woodchips (WC) as a core medium has increased in bioreactors that reduce nitrogen from runoff [17] and agricultural drainage, and this natural media is cost effective, easily obtainable, and has a functional lifespan [18]. In addition, some waste plants, such as cockle shell, coconut husk, and flowers, were also used as filter media to remove nitrogen and phosphorus $[19,20]$. Furthermore, the use of natural filter media can be in accordance with the trend toward sustainable water treatment processes. Our society today needs energy-efficient and resource-recovering technologies, such as anaerobic digestion producing energy in the form of methane, struvite precipitation recovering phosphate and ammonia, and membrane processes with low energy consumption and convenient compact operation. As a result, the re-use of waste in filter processes reduces energy consumption and increases recycling waste [21,22].

Although a variety of studies on the removal of pollutant as from NPS have been carried out, the effect of TSS on the removal of organic carbon and nutrients is not clear. Therefore, this study attempts to find the correlation effect of removal between media and contaminants in the filter system. The primary objective of this research was to determine the removal efficiency of each pollutant in a variety of mixed media and to characterize the effect of TSS on the removal of each pollutant. This study aims to (1) find the removal efficiency for TSS, BOD, COD, T-N, and T-P for different media and hydraulic conditions, (2) investigate the correlation of each contaminant with TSS removal, (3) determine the organic carbon (BOD and COD) removal mechanism, and (4) explain the adsorption process of T-N and T-P by comparing the removal ratios. 


\section{Materials and Methods}

\subsection{Characteristics of Media}

Sand, BA, and WC were purchased from Changsung (Seongnam, Korea), ILA Green Co., LTD (Seocheon, Korea), and Kyelm (Daegu, Korea), respectively. Before use, the media were grouped by particle size by passing them through a sieve. The desired particle size was selected, and the physical and chemical properties, such as the uniformity coefficient $\left(D_{60} / D_{10}\right)$, porosity $\left(100 \times\left(1-\rho_{b} / \rho_{p}\right)\right.$, and composition, are listed in Table 1. Silica is the major component in sand and BA. The portions of metal oxide $\left(\mathrm{Al}_{2} \mathrm{O}_{3}\right.$ and $\left.\mathrm{Fe}_{2} \mathrm{O}_{3}\right)$ is over $30 \%$ for BA. WC were composed of $95 \%$ water, organic sand had the lowest uniformity coefficient, and WC had the highest porosity and particle size. Before the media were used, they were soaked in distilled water for $48 \mathrm{~h}$ to remove impurities on their surfaces.

Table 1. Physical and chemical properties for sand, bottom ash, and wood chip.

\begin{tabular}{cccc}
\hline Type of Filter Media & Sand & Bottom Ash & Wood Chip \\
\hline \multirow{3}{*}{ Main Composition ${ }^{a}$} & $\mathrm{SiO}_{2}: 70 \%$ & $\mathrm{SiO}_{2}: 55 \%$ & Water and Organic: $95 \%$ \\
& $\mathrm{Na}_{2} \mathrm{O}: 13.3 \%$ & $\mathrm{Al}_{2} \mathrm{O}_{3}: 22.5 \%$ & $\mathrm{~K} \%: 1 \%$ \\
Particle size & $\mathrm{CaO}: 10 \%$ & $\mathrm{Fe}_{2} \mathrm{O}_{3}: 10 \%$ & $\mathrm{CaO}: 2 \%$ \\
Uniformity coefficient & $0.85-2 \mathrm{~mm}$ & $0.5-1.2 \mathrm{~mm}$ & $\mathrm{MgO}: 1 \%$ \\
Porosity & 1.2 & 1.8 & $2.00-4.76 \mathrm{~mm}$ \\
& $35-40 \%$ & $45-55 \%$ & $70-80 \%$ \\
\hline
\end{tabular}

a The scanning electron microscopy-energy dispersive spectroscope (SEM-EDS, VEGA II TESCAN, USA Inc.) was used.

\subsection{Lab-Scale Experiments}

All experiments were conducted in the lab-scale with the desired initial hydraulic conditions using an acrylic reactor. The influent was mixed continuously to prevent the settlement of particles, and was fed into the reactor by a pump, which controlled the flow rate and determined the total volume treated. The reactor dimensions were $600 \mathrm{~mm}(\mathrm{~W}) \times 600 \mathrm{~mm}(\mathrm{~L}) \times 700 \mathrm{~mm}(\mathrm{H})$, and the influent was in the down-flow mode (Figure 1). To scale the dimension up for the field operation, the constant HC had to be operated by higher pump capacity. The bed was packed by combining two or three types of media to determine the effect of multi layers. For example, sand was in the top (first layer) and BA was in the bottom (second) layer (S-BA). When two or three media were packed, the depth and volume of each media were 30 and $20 \mathrm{~cm}$, and 108 and $72 \mathrm{~L}$, respectively. WC were not chosen as the first layer in order to protect the suspension.

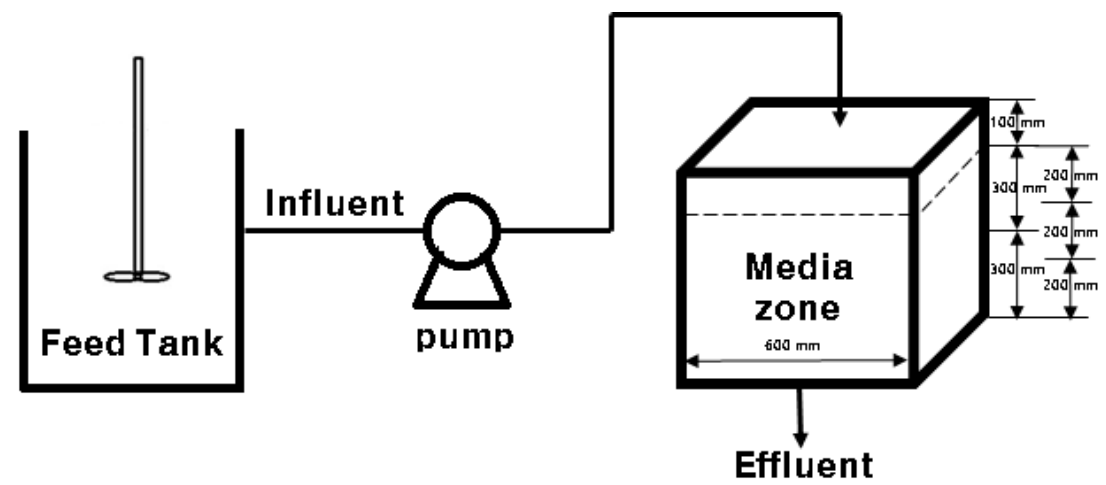

Figure 1. Schematic of experiment reactor. 


\subsection{Operation Conditions}

ME (2016) specified that the influent concentration of TSS ranged from 150-350 mg/L, and its $\mathrm{HC}$ was $20 \mathrm{~m}^{3} / \mathrm{m}^{2} / \mathrm{h}$ when testing filtration at a nonpoint source treatment facility. The stormwater runoff influent was provided from a local road in Cheonan City after a rainfall event, and TSS was set at 150-350 mg/L by adding particles and diluting with DI when it fell out of the range. TSS size distribution for the influent was also analyzed [23], and was composed of $70-80 \%$ TSS less than $63 \mu \mathrm{m}$ and $20-30 \%$ TSS ranging from $63-200 \mu \mathrm{m}$. The total volume of $3 \mathrm{~m}^{3}$, as influent, was fed and the hydraulic retention time (HRT) was set to $3.6 \mathrm{~min}$. Three different HCs, 10, 20, and $30 \mathrm{~m} / \mathrm{h}$, were selected as low, standard, and high conditions to determine the effect of HC. The initial concentrations of BOD, COD, T-N, T-P, and $\mathrm{pH}$ ranged from $12.1-16.2 \mathrm{mg} / \mathrm{L}, 17.7-42.4 \mathrm{mg} / \mathrm{L}$, $2.2-4.9 \mathrm{mg} / \mathrm{L}, 0.3-1.0 \mathrm{mg} / \mathrm{L}$, and 5.8-6.3, respectively.

\subsection{Contaminant Analysis}

Laboratory tests for the six mixed media types were carried out at three different HCs, and for each condition the test was conducted four times. The collected water samples that went through the filtration process were analyzed at least three times by the following methods: Gravimetrical filtration for TSS, membrane electrode for $\mathrm{BOD}, \mathrm{KMnO}_{4}$ for $\mathrm{COD}$, and absorption metric analysis by a UV-1201 Spectrophotometer (Shimadzu, Tokyo, Japan) for T-N and T-P, which were recommended by the Guideline manual of ME [24].

\section{Results and Discussion}

\subsection{Removal Efficiency of Each Contaminant}

Figure 2a and Figure S1 show the removal efficiencies of TSS, BOD, COD, T-N, and T-P for the six mixed media types and the three HCs of 10, 20, and $30 \mathrm{~m} / \mathrm{h}$. The values are summarized in Table S1, presenting removal efficiency and standard deviation in the form of: removal efficiency \pm standard deviation. According to the results, several conclusions were determined: (1) Among the five pollutants, TSS showed the highest removal efficiency; (2) lower HC values induced higher removal efficiency; (3) the maximum and minimum removal values were obtained with S-BA and BA-S-WC, respectively; and (4) the removal efficiency order followed by media type and HC were not changed, regardless of water quality, except for T-P. Similarly to Hamoda et al. (2004) were removal efficiencies of $70 \%$, $38 \%$, and $54 \%$ for TSS, COD, and BOD, respectively, were obtained [25], the highest removal efficiency was obtained for TSS among several pollutants. The tendency towards a higher removal efficiency of S-BA for BOD, COD, T-N, and T-P in accordance with TSS revealed that some portion of the pollutants existed in solid form and were unpredictably removed by media, such as TSS, resulting in a strong correlation with TSS removal. The lower removal efficiency observed with WC as a medium suggested that WC did not play a significant role in the removal of particles. A new approach is required to investigate filtration effects, correlations, and removal mechanisms for particulate and dissolved pollutants.

\subsection{Removal of TSS}

Figure 2a shows the removal efficiency (\%) of TSS. Note that to precisely investigate the correlation of $\mathrm{HC}$ and media types, the $x$-axis was intentionally ordered from the highest to lowest removal efficiency. In Figure 2a, the removal efficiency of TSS ranged from $72 \%$ to $93 \%$, depending on the type of media, and it decreased with an increase in HC. The removal efficiency sequence by media type was as follows: S-BA > BA-S > S-WC-BA > BA-WC-S > S-BA-WC > BA-S-WC, which is the same order for the removal of other contaminants.

According to the Korean regulation for non-point source pollution treatment for field facilities, TSS removal efficiency is required to reach at least $80 \%$ at $20 \mathrm{HC}$ using the proper filtering equipment for stormwater treatment [23]. Meeting the $80 \%$ efficiency at 10 and $20 \mathrm{~m} / \mathrm{h}$ of HC occurs regardless 
of media type-however, only the use of S-BA and BA-S results in over $80 \%$ efficiency at $30 \mathrm{~m} / \mathrm{h}$ of $\mathrm{HC}$. It can be assumed that $\mathrm{HC}$ is a more critical parameter to determine the removal efficiency in this study, although this result needs to be evaluated with a quantitative approach.
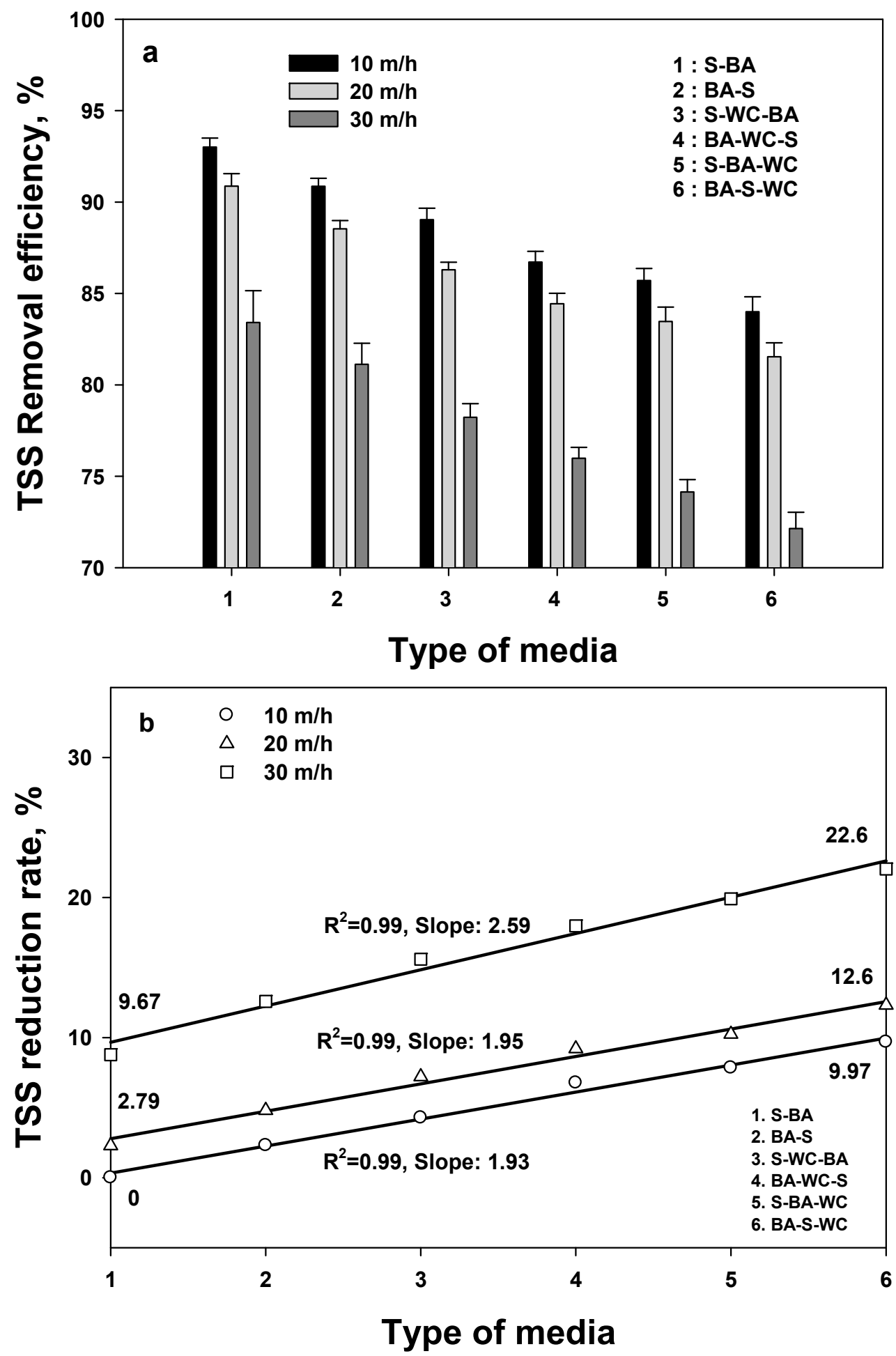

Figure 2. Total suspended solids' (TSS) removal efficiencies (\%): (a) TSS reduction rates (\%) of TSS removal efficiency (b) for six media types and at three different hydraulic conductivities (HCs) $(10,20$, and $30 \mathrm{~m} / \mathrm{h})$. 
To certify the effect of the type of media and HC, the reduction rate of the removal efficiency was shown in Figure 2b, which are similar but different. Each value (symbol) is the reduction rate (\%) compared to the value of $93 \%$ removal efficiency of TSS at $10 \mathrm{~m} / \mathrm{h}$ HC and S-BA as a reference value (zero value). A linearly fitted regression line was added, including the value of the slope and y-intercept, referred to S-BA. These obtained values express the reduction rate of the removal efficiency by changing the type of media and HC, respectively. In Figure $2 b$, the value of the slope and y-intercept were obtained as 1.93, 1.95, and 2.59, and 0, 2.79, and 9.67 at 10, 20, and $30 \mathrm{~m} / \mathrm{h}$, respectively. According to the slope, at $10 \mathrm{HC}$, the removal efficiency of TSS gradually decreased by $1.93 \%$, depending on the type of media, and was finally reduced to $9.97 \%$ at BA-S-WC, compared with S-BA. Between $10 \mathrm{HC}$ and $20 \mathrm{HC}$, there is no significant difference in slope, whereas the value of the slope at $30 \mathrm{HC}$ increased to 2.59 , which is a $34 \%$ higher value than 1.93 . This means TSS removal was $34 \%$ more affected by media type at $30 \mathrm{HC}$ than at $20 \mathrm{HC}$.

When directly comparing the y-intercept, the reduction rate increased to $2.79 \%$ and $9.67 \%$ at $20 \mathrm{HC}$ and $30 \mathrm{HC}$, respectively. Higher HC accelerates the decrease in the removal efficiency. This observation was supported by Hatt et al. [10] who carried out their lab test using $80 \%$ sandy loam. The authors concluded that hydraulic condition was a function of the sediment being accumulated in TSS. Therefore, it is assumed that the higher reduction of removal efficiency at $30 \mathrm{HC}$ was due to the TSS that accumulated on the porous media. Consequently, the TSS removal decreased more at $30 \mathrm{HC}$, based on the type of media and HC.

\subsection{Removal of $B O D$ and $C O D$}

BOD and COD, as organic contamination, were analyzed, and removal efficiencies are shown in Figure S1. The initial concentration ranged from $12 \mathrm{mg} / \mathrm{L}$ to $16 \mathrm{mg} / \mathrm{L}$ for BOD and from $22 \mathrm{mg} / \mathrm{L}$ to $32 \mathrm{mg} / \mathrm{L}$ for COD, and the removal efficiency ranged from $47.0 \%$ to $66.9 \%$ for BOD and from $35.8 \%$ to $51.5 \%$ for COD. The maximum removal efficiency sharply decreased to $\sim 26 \%$ for BOD and $\sim 41 \%$ for COD, compared to $93 \%$ for TSS. In addition, the COD removal efficiency was always lower than the BOD removal efficiency.

In general, organic carbon was divided into particulate organic carbon (POC) and dissolved organic carbon (DOC) [26,27]. Therefore, the removal of organic carbon could be derived from the POC, removed by media such as TSS. Figure 3a shows that the reduction rate of BOD is similar to that of the TSS trend, supporting the idea that BOD were primarily removed by the POC. The obtained values were $3.15,3.33$, and 2.85 as the slope and $0,3.38$, and 15.1 as the $y$-intercept, which shows higher values than the TSS. The increased values compared to the TSS means that BOD removal was more influenced by both HC and the type of media than by TSS. According to the fact that the variation in the slope was within $10 \%$, the effect of the type of media was stable regardless of $\mathrm{HC}$.

From Figure $3 \mathrm{~b}$ for COD, the slope was calculated as 4.09, 2.79, and 2.35, and the y-intercept was calculated as $0,9.65$, and 19.9 at 10, 20, and $30 \mathrm{HC}$, respectively. Although COD is also an indicator of organic matter in the water, similar to BOD, the value of the slope at $10 \mathrm{HC}$ was much higher and rapidly decreased by increasing HC. This difference clarified that COD was more sensitively removed at lower HCs based on the type of media than BOD.

Based on the different slope and y-intercept compared to TSS, the removal of BOD and COD was not only caused by filtration. To prove the correlation between TSS and BOD removal, Figure 4a was drawn with the removal efficiency ratio of BOD to TSS, along with six media types. Ideally, if BOD was only removed by media as a form of POC, the value of the $y$-axis should be parallel, and only $\mathrm{HC}$ could shift the value. As a result, the different ratio obtained from Figure 4a may suggest that other processes, such as biodegradation or adsorption, are involved in the removal of BOD. 


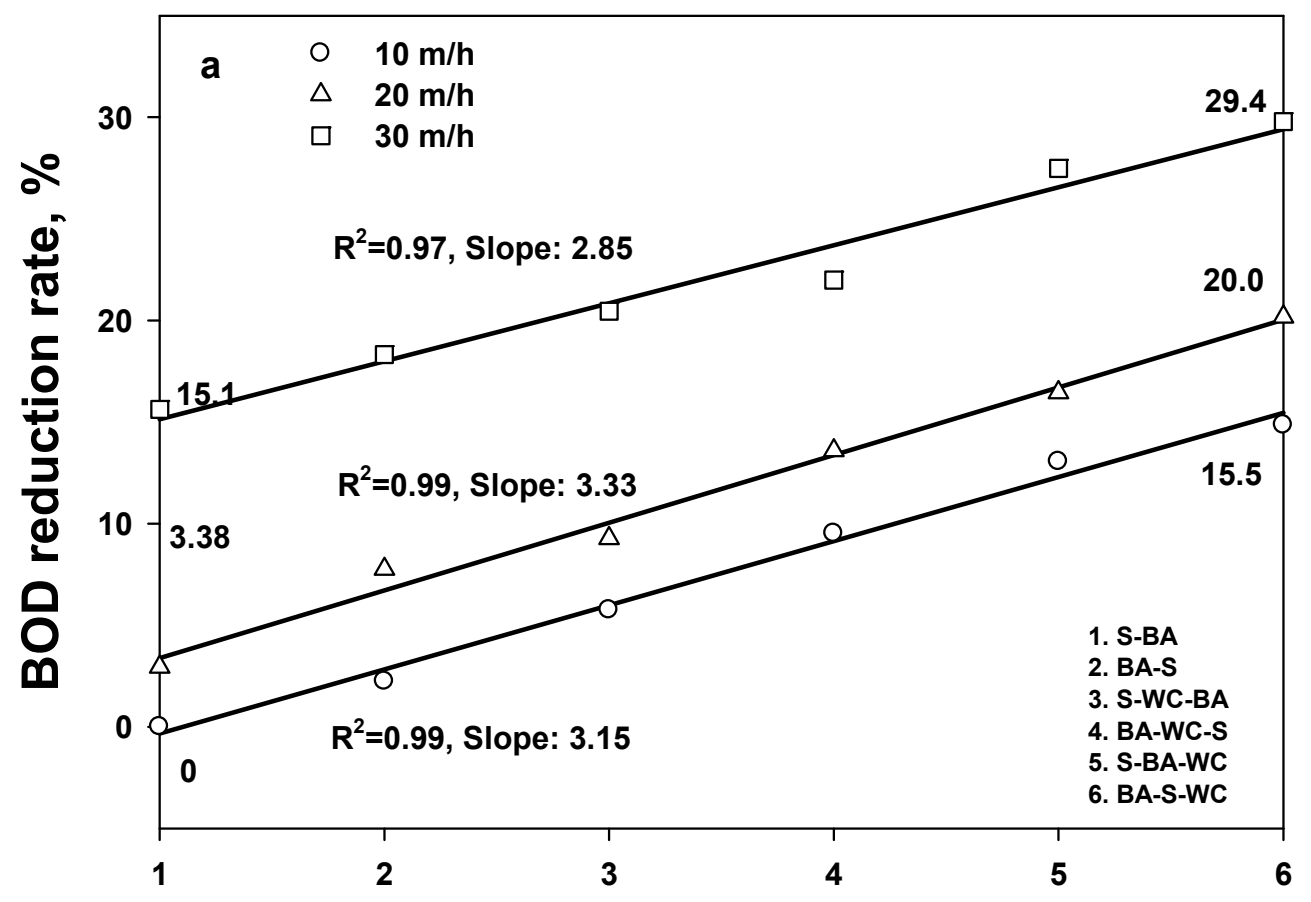

Type of media

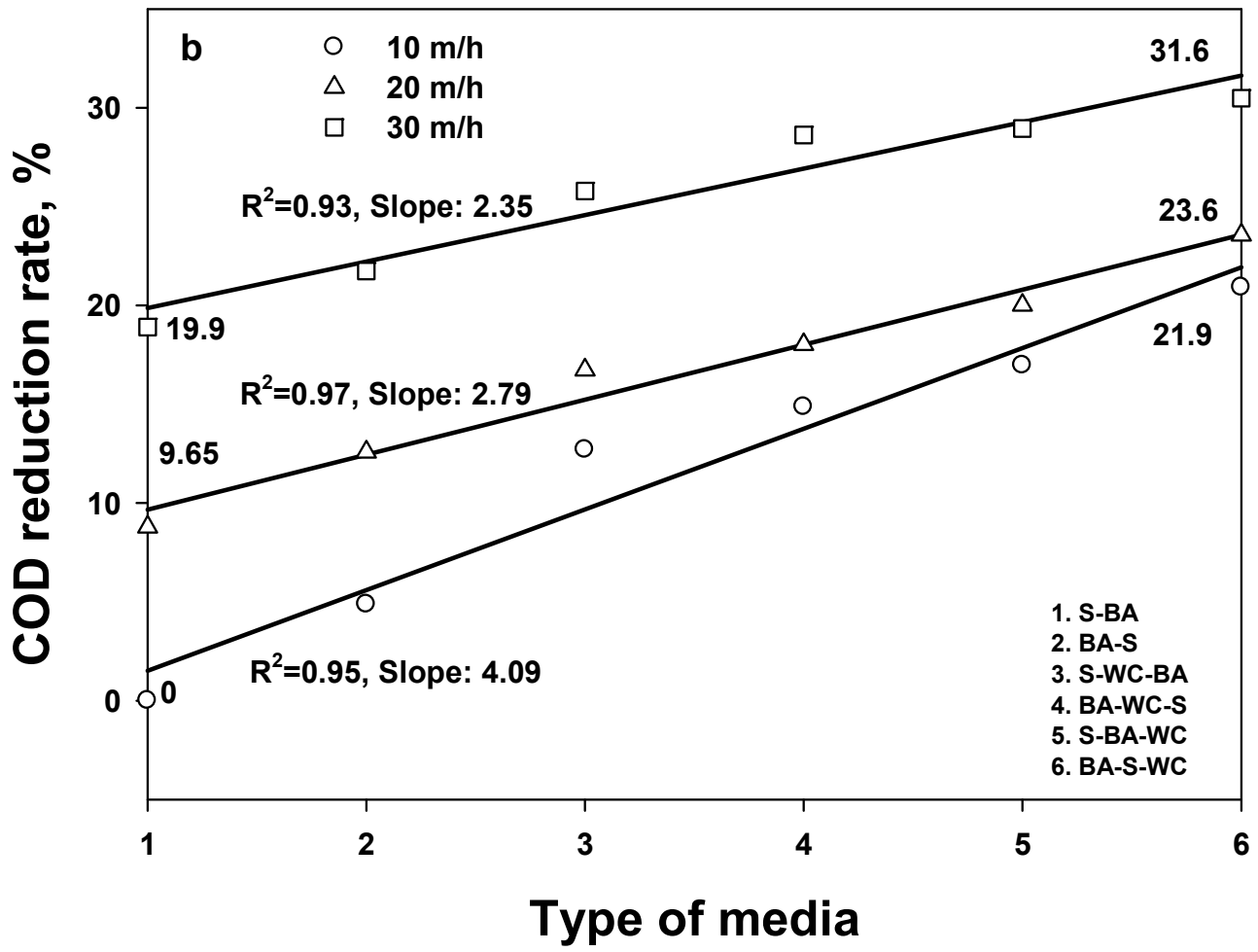

Figure 3. Reduction rates (\%) of removal efficiency for BOD (a) and COD (b) for six media types and three different HCs $(10,20$, and $30 \mathrm{~m} / \mathrm{h})$. 

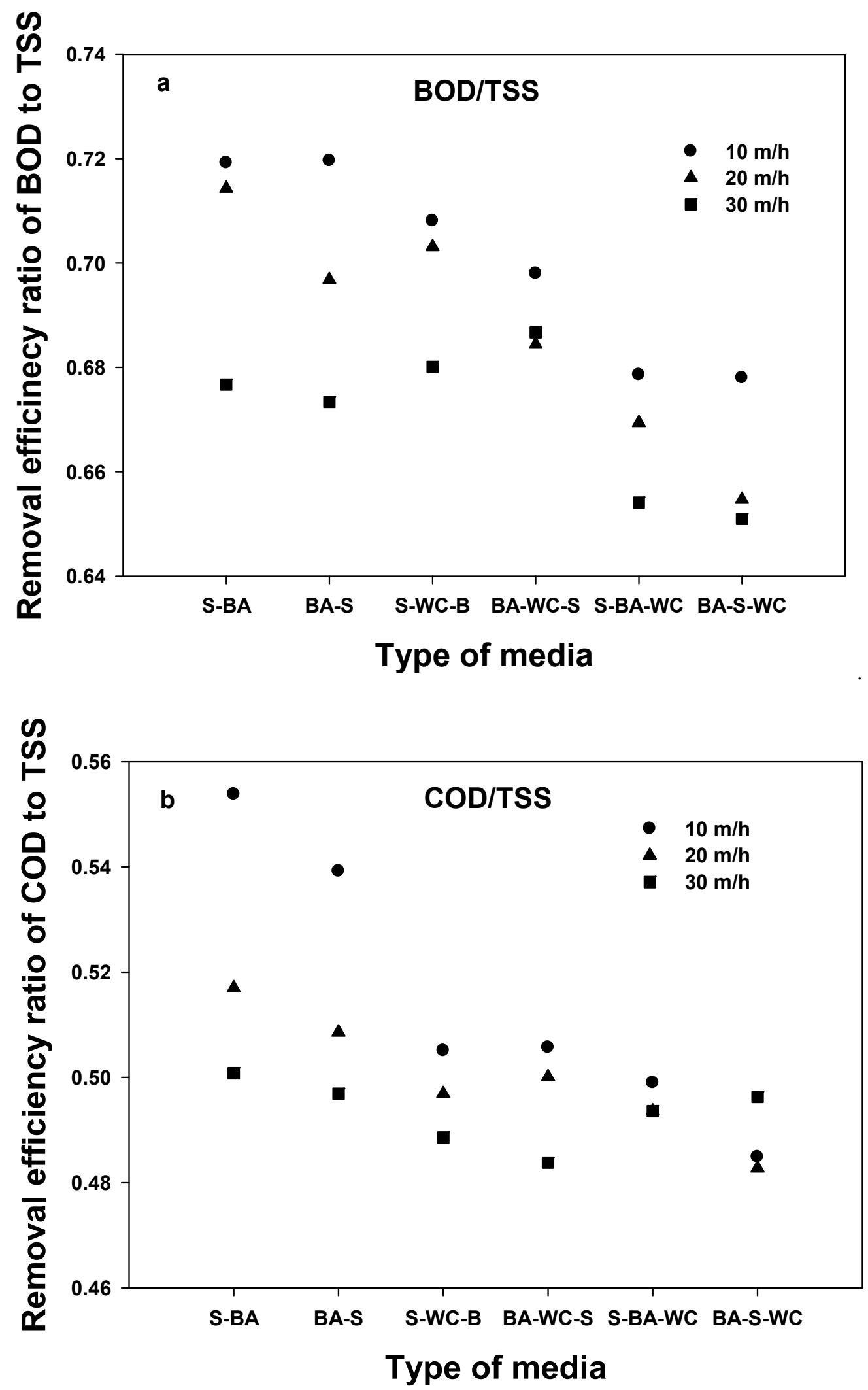

Figure 4. Removal efficiency ratios of BOD to TSS (a) and COD to TSS (b) for six media types and three different HCs $(10,20$, and $30 \mathrm{~m} / \mathrm{h})$. 
The three-mixed media show a relatively lower ratio than the two-mixed media. The lower value at three-mixed media indicates that the effect of filtration is more influenced by BOD removal. According to Figure $4 \mathrm{~b}$, it was detected that the variation in the $y$-value for the two-mixed media (S-BA and BA-S) was relatively higher than for the three-mixed media, similar to BOD. Therefore, HC had a greater effect on the removal efficiency of BOD and COD for two-mixed media.

Based on the removal efficiency ratio of BOD (COD) vs TSS ( $y$-axis, Figure 4) both being less than 1.0, and the different removal phenomena between BOD and COD, McDowell and Fisher [28] reported that the concentration of dissolved organic matter was 10 times and 2 to 5 times greater than that of particulate organic matter during the base and high flow of river water, respectively. The ratio of COD to BOD is commonly used in wastewater treatment to estimate the biodegradability of organic pollutants as a biodegradability index (BI) $[29,30]$. Figure 5 shows the influent and effluent BI to identify the effects of media on the removal of organic matter. A previous study [31,32] mentioned that BI of less than 1.7, 1.7-10, and more than 10 corresponded to easily and entirely biodegradable organic contents, incompletely biodegraded contents, and no biodegradable organic contents, respectively. In this experiment, since most of the initial ratios ranged from 1.6 to 1.9 , the organic matter could be partially biodegradable. Furthermore, after filtration, all the increased effluent BI would demonstrate that some of the organic pollutants were first removed by biodegradation before the BI increased [32]. Therefore, the values of BI and increased BI after filtration indicate that some organic carbon can be removed by biodegradation. Ho et al. [33] reported that organic pollutants, such as MIB and geosmin, is able to be biodegraded by a sand filter.

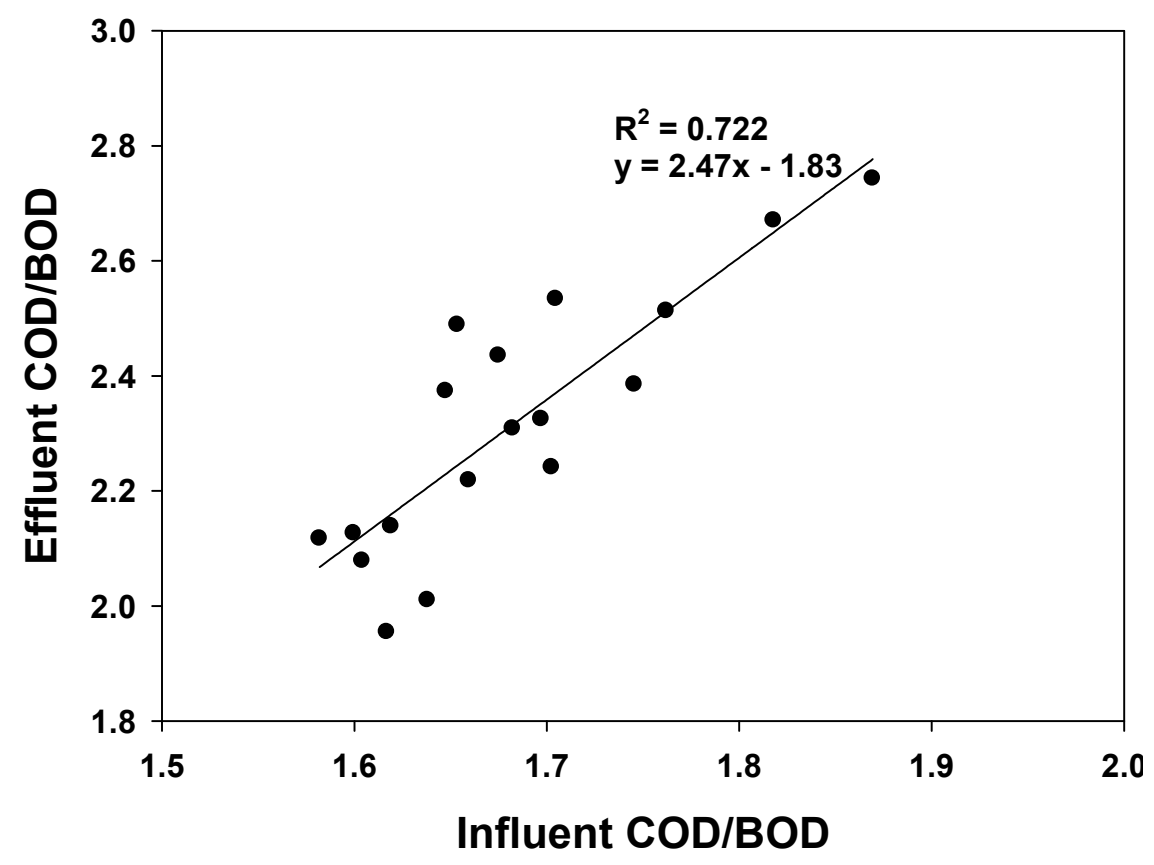

Figure 5. Comparison of influent COD/BOD ( $x$-axis) to effluent COD/BOD ( $y$-axis).

Other alternative approaches were considered by Davise [34], who studied hydraulic conditions. For the conventional process regarding activated sludge, 5 to $14 \mathrm{~h}$ hydraulic retention time (HRT) is required [34] to complete biodegradation for organic carbon. Biodegradability was also estimated by the ratio of COD to T-N, referred to as $\mathrm{C} / \mathrm{N}$ and COD:N:P. The $\mathrm{C} / \mathrm{N}$ is an important key in the field of wastewater treatment using activated sludge, and COD:N:P was recommended to be 100:5:1 and 250:5:1 for aerobic and anaerobic treatments, respectively [30]. In comparison with the values, the obtained value in this experiment is 10:1 for $\mathrm{C} / \mathrm{N}$ and 50:5:1 for COD:N:P, respectively. Therefore, biodegradability during filtration can be ignored in the current hydraulic condition. 
The other possibility is BOD adsorption by the media's surface. Adsorption for dissolved organic carbon (DOC) occurs more rapidly than biodegradation using soil treatment [35], and the DOC is primarily controlled by adsorption to the soil's surface [36]. However, due to the similarity of the removal shape of COD with that of TSS, as well as its low removal ratio, the adsorption effect is lesser than the filtration effect. Consequently, organic carbon removal mainly occurrs by particulate organic matter, and the different BOD and COD removal efficiencies are likely due to the effect of the particle distribution of POM.

\subsection{SS-T-N and SS-T-P}

The removal efficiencies of T-N and T-P are drawn in Figure S1. Removal efficiencies of $40 \%$ to $55 \%$ and $50 \%$ to $63 \%$, respectively, were achieved, with T-P obtaining the highest removal efficiency for all conditions, other than T-N. According to Figure $6 \mathrm{a}, \mathrm{b}$, the removal trend of T-N is very similar to that of other contaminants, but that for T-P is different when used in BA-S. Therefore, T-P could be differently removed compared to T-N and TSS.
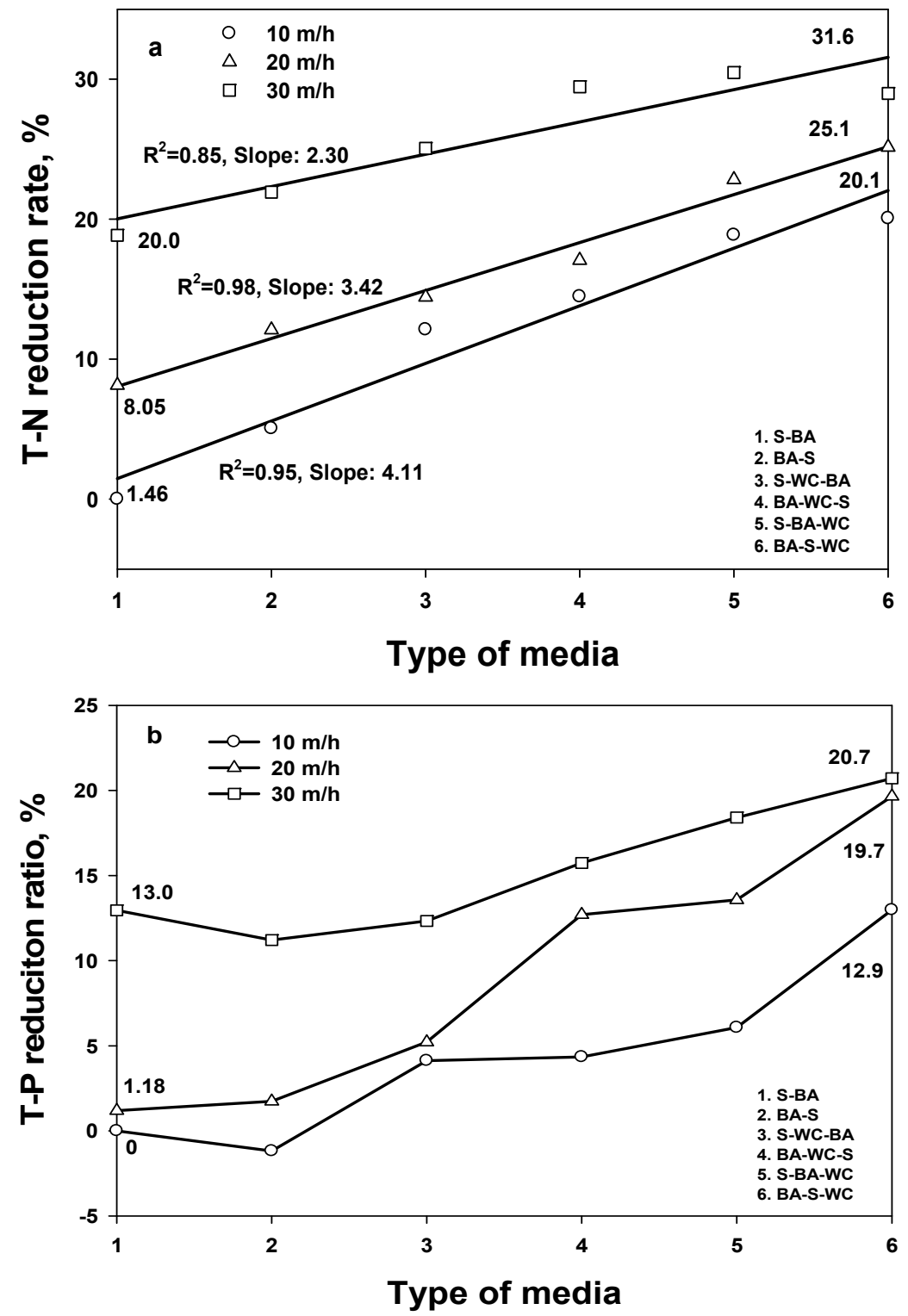

Figure 6. Reduction rates of removal efficiency for T-N (a) and T-P (b) for six media types and three different HCs $(10,20$, and $30 \mathrm{~m} / \mathrm{h})$. 
In general, $\mathrm{T}-\mathrm{N}$ is the sum of nitrate $\left(\mathrm{NO}_{3}{ }^{-}\right)$, nitrate $\left(\mathrm{NO}_{2}{ }^{-}\right)$, and organic nitrogen and ammonia $\left(\mathrm{NH}_{3}\right)$ (all expressed as $\left.\mathrm{N}\right)$, and T-P consists of orthophosphates $\left(\mathrm{PO}_{4}{ }^{3-}\right)$ which is the dominant species in waterbodies, condensed phosphates, and organic phosphates [37]. Previous study concluded that bioretention during filtration using WC [38], can improve the removal efficiency for nitrogen. Although nutrients were partly composed of organic materials and could be treated by biodegradation, our result did not show the positive effect of the addition of WC. It would be due to the very high HC, HRT, and a low COD:N:P ratio resulting in no biodegradation.

The reduced slope value from 4.11 to 2.30 in increase with HC (Figure 6a) indicates that at lower $\mathrm{HC}$, the removal efficiency of nitrogen significantly depends on the type of media.

Furthermore, in Figures $6 \mathrm{~b}$ and $7 \mathrm{a}$, the removal ratio of TSS to T-N and T-P was less than 1.0, confirming that a portion of T-N and T-P exists in a dissolved form. In Figure 7a, the result of T-N is approximately similar to that of BOD and COD, meaning it can be concluded that filtration plays a key role in T-N removal-or more specifically, the effect of media is disregarded in the removal of dissolved T-N.

Although T-N and T-P are considered to be nutrients, the removal of T-P was higher than that of T-N for all conditions. An explanation for this may be that the dissolved T-P is able to be removed not only by filtration, but also adsorption. Phosphate $\left(\mathrm{PO}_{4}{ }^{3-}\right)$ is the main species in T-P and is a negatively-charged ion in solutions. In fact, the initial concentration of T-N is much higher than T-P, which can increase the removal capacity of T-N by adsorption. However, phosphate has a better affinity during adsorption using surface silica [39] due to the different electron charge and anion structures, although the ratio of the initial concentration of TN to TP was 10:1.

The highest T-P removal occurred at BA-S, not S-BA, which differed completely to other contaminates. This phenomena may be due to how BA is maximized at BA-S, because higher concentrations accelerate solute removal kinetics and sorption capacities during adsorption. Therefore, it is shown that the first contact for BA can improve the removal efficiency of T-P by adsorption.

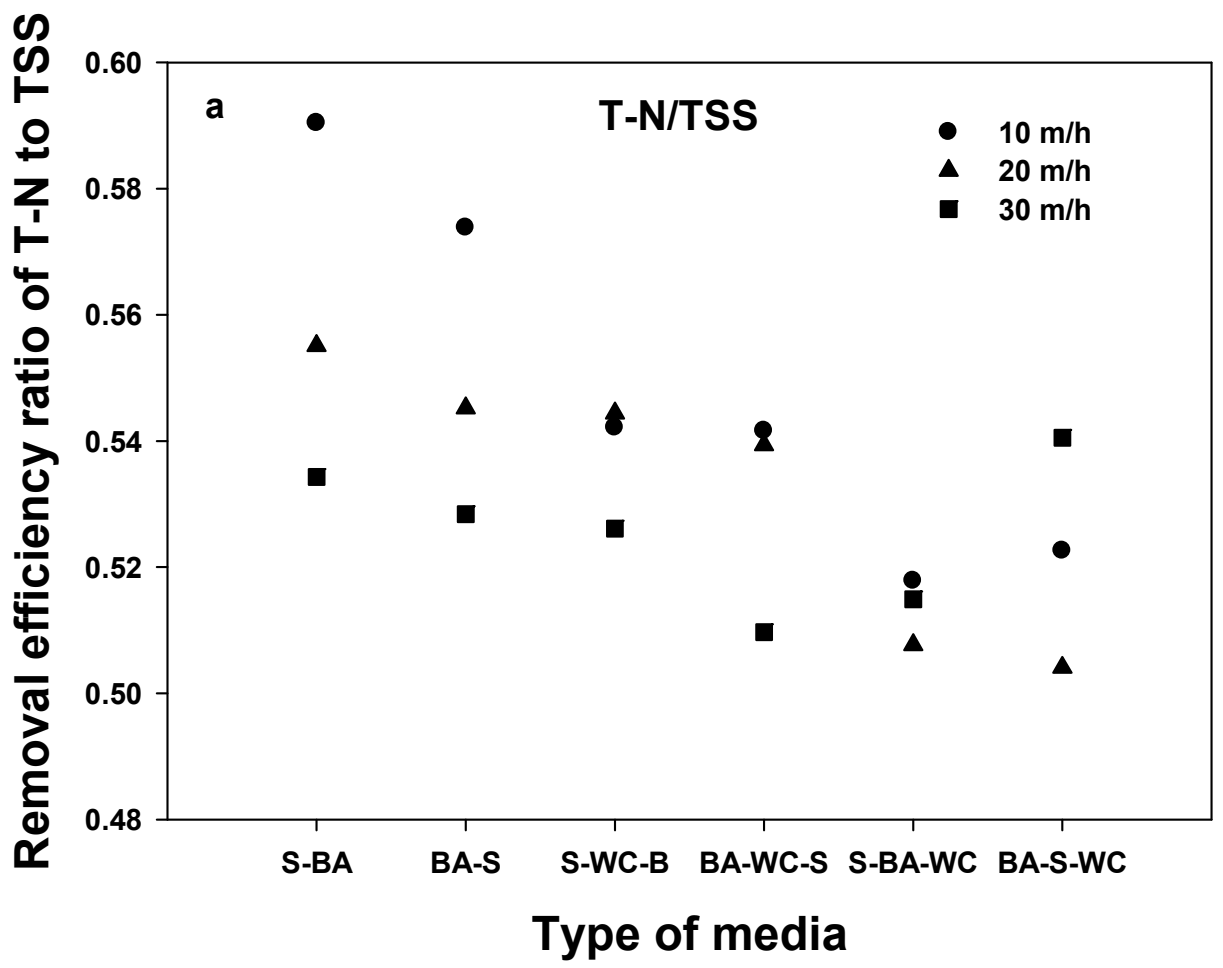

Figure 7. Cont. 


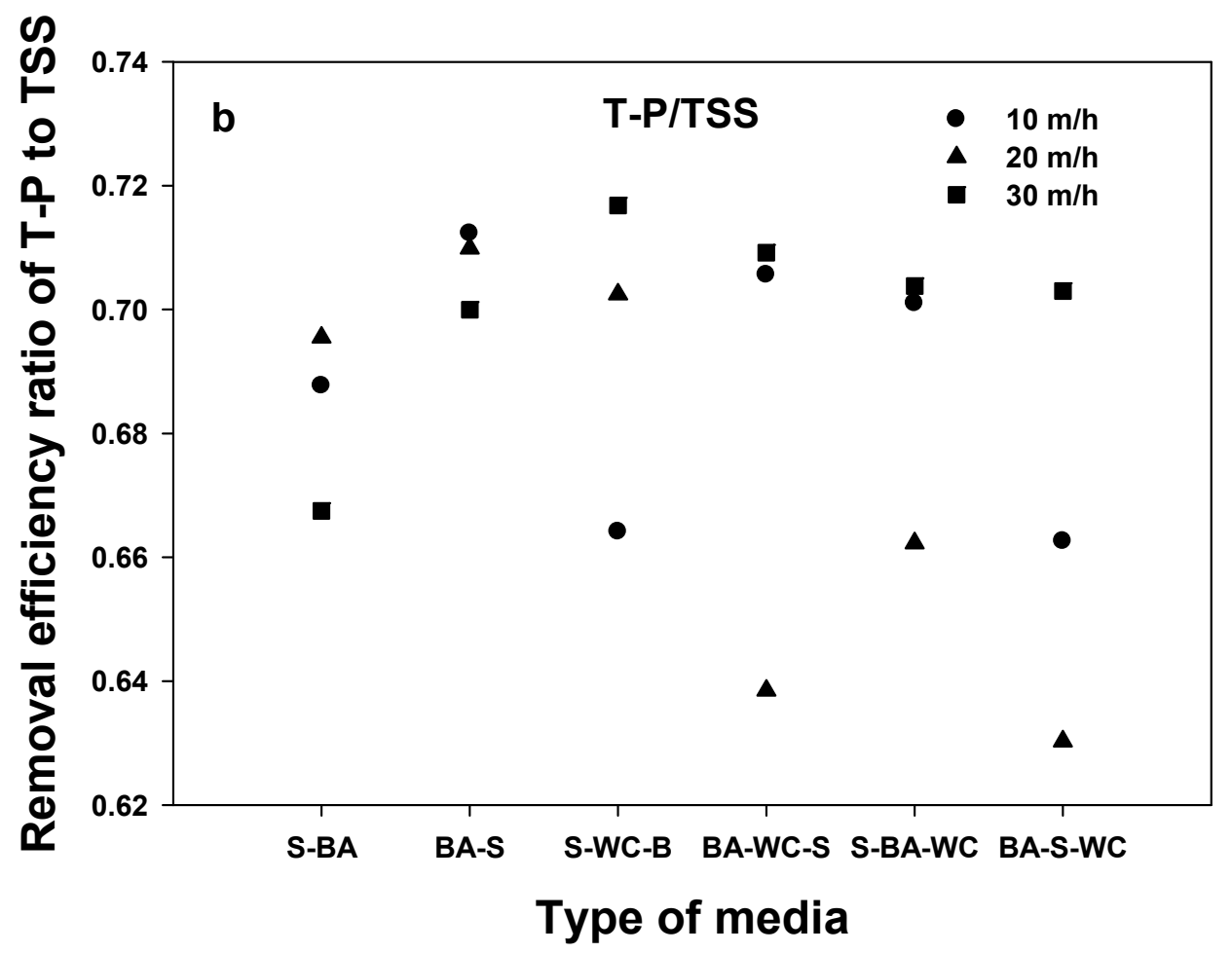

Figure 7. Removal efficiency ratios of T-N to TSS (a) and T-P to TSS (b) for six media types and three different HCs $(10,20$, and $30 \mathrm{~m} / \mathrm{h})$.

However, according to the fact that there is no enhanced efficiency in the use of BA-WC-S and BA-S-WC, which are also the first contacts of BA, it would be assumed that the presence of BA would be ignored due to the lower amount of BA. Consequently, an appropriate amount of BA, similar to the adsorbent, is required to increase T-P removal.

\section{Conclusions}

In this laboratory-based experiment for stormwater treatment using filtration, the main results and conclusions are summarized as follows:

- Based on the TSS removal efficiency, all mixed filtration media obtained an $80 \%$ removal efficiency at 10 and $20 \mathrm{HC}$, which satisfies the Korean regulations for stormwater treatment. The two mixed media obtained at least a $15 \%$ higher removal efficiency than the three mixed media.

- The comparison of removal efficiencies for five different water quality indexes shows that TSS has the highest removal efficiency (regardless of filter media type), followed by $\mathrm{T}-\mathrm{P}>\mathrm{BOD}>\mathrm{COD}=\mathrm{T}-\mathrm{N}$, confirming that the filtration process is optimized for TSS.

- Similar removal efficiency trends of BOD, COD, and T-N with TSS indicate that the removal of $\mathrm{BOD}, \mathrm{COD}$, and T-N was primarily affected by the portion of the particle form.

- TSS was less sensitive to filter type and HC than other pollutants. Among a variety of experimental conditions, T-N had the highest variation, depending on the HC at S-BA and on the type of media at $10 \mathrm{HC}$.

- Through comparisons of BI, HRT, and C:N, it was found that biodegradation during filtration cannot occur.

- Unlike other pollutants, the highest removal efficiency was observed using BA-S for T-P. This corresponds to the adsorption effect for BA.

- Increased water quality using BA and WC demonstrated its capability and sustainability due to its low-cost and low-energy consumption factors, despite lower removal efficiency for 
water and wastewater treatment. In order to enhance the water quality and quantity treated, the system needs to be determined on the optimized operating parameters depending on influent concentrations or target pollutants.

Supplementary Materials: The following are available online at http:/ /www.mdpi.com/2073-4441/10/8/1069/ $\mathrm{s} 1$, Table S1. Removal efficiency and stand deviation in the form as: removal efficiency \pm standard deviation for each pollutant for different filter media types and HCs (10, 20, and $30 \mathrm{~m} / \mathrm{h})$, Figure S1 Removal efficiencies of BOD (a), COD (b), T-N (c) and T-P (d) for six media types and three different HCs.

Author Contributions: H.J.K. designed the framework of this study and did experiments; J.-W.C. analyzed the all of the data; T.-H.K. and J.-S.P. provided comments on the table and figure. All of authors discussed first review comments and the final manuscript proofreading.

Funding: This work was carried out with the support of "Cooperative Research Program for Agriculture Science and Technology Development (Project No. PJ012215042017)" Rural Development Administration, Republic of Korea.

Conflicts of Interest: The authors declare no conflict of interest.

\section{References}

1. Carpenter, S.R.; Caraco, N.F.; Correll, D.L.; Howarth, R.W.; Sharpley, A.N.; Smith, V.H. Nonpoint pollution of surface waters with phosphorus and nitrogen. Ecol. Appl. 1998, 8, 559-568. [CrossRef]

2. Morée, A.L.; Beusen, A.H.W.; Bouwman, A.F.; Willems, W.J. Exploring global nitrogen and phosphorus flows in urban wastes during the twentieth century. Glob. Biogeochem. Cycles 2013, 27, 836-846. [CrossRef]

3. USEPA. Guidance for Water Quality-Based Decisions, The TMDL Process, 1991. Available online: https: / / nepis.epa.gov / Exe/ZyPDF.cgi/00001KIO.PDF?Dockey=00001KIO (accessed on 11 July 2018).

4. Ministry of Environment (ME). Key Projects of the Water Environment Policy Bureau, 2015. Available online: http:/ / www.me.go.kr/home/ file/readDownloadFile.do?fileId=116670\&fileSeq=14\&openYn=Y (accessed on 11 July 2018).

5. Horner, R.R.; Skupien, J.J.; Livingston, E.H.; Shaver, H.E. Fundamentals of Urban Runoff Management: Technical and Institutional Issues; Terrene Institute: Washington, DC, USA, 1994; Available online: http:/ /agris.fao.org/ agris-search/search.do?recordID=US9536404 (accessed on 11 July 2018).

6. Berkman, H.E.; Rabeni, C.F. Effects of siltation on stream fish communities. Environ. Biol. Fish. 1987, 18, 285-294. [CrossRef]

7. Matilainen, A.; Vepsäläinen, M.; Sillanpää, M. Natural organic matter removal by coagulation during drinking water treatment: A review. Adv. Colloid Interface Sci. 2010, 159, 189-197. [CrossRef] [PubMed]

8. Nam, J.H.; Lee, S.H.; Choi, J.W.; Hong, S.W.; An, B. Enhanced removal of phosphate on modified ion exchanger with competing ion. J. Korean Soc. Water Wastewater 2013, 27, 121-128. [CrossRef]

9. Hipp, J.A.; Ogunseitan, O.; Lejano, R.; Smith, C.S. Optimization of stormwater filtration at the urban/watershed interface. Environ. Sci. Technol. 2006, 40, 4794-4801. [CrossRef] [PubMed]

10. Hatt, B.E.; Fletcher, T.D.; Deletic, A. Hydraulic and pollutant removal performance of fine media stormwater filtration systems. Environ. Sci. Technol. 2008, 42, 2535-2541. [CrossRef] [PubMed]

11. Davis, A.P.; Shokouhian, M.; Sharma, H.; Minami, C. Laboratory study of biological retention for urban stormwater management. Water Environ. Res. 2001, 73, 5-14. [CrossRef] [PubMed]

12. Somdee, T.; Wibuloutai, J.; Somdee, T.; Somdee, A. Biodegradation of the cyanobacterial hepatotoxin [Dha7] microcystin-LR within a biologically active sand filter. Water Sci. Technol. 2014, 14, 672-680. [CrossRef]

13. Cho, K.W.; Song, K.G.; Cho, J.W.; Kim, T.G.; Ahn, K.H. Removal of nitrogen by a layered soil infiltration system during intermittent storm events. Chemosphere 2009, 76, 690-696. [CrossRef] [PubMed]

14. Lin, C.Y.; Yang, D.H. Removal of pollutants from wastewater by coal bottom ash. J. Environ. Sci. Health 2002, 37, 1509-1522. [CrossRef]

15. Kandel, S.; Vogel, J.; Penn, C.; Brown, G. Phosphorus retention by fly ash amended filter media in aged bioretention cells. Water 2017, 9, 746. [CrossRef]

16. Gupta, V.K.; Mittal, A.; Jhare, D.; Mitaal, J. Batch and bulk removal of hazardous colouring agent rose Bengal by adsorption techniques using bottom ash as adsorbent. RSC Adv. 2012, 2, 8381-8389. [CrossRef]

17. Schipper, L.A.; Robertson, W.D.; Gold, A.J.; Jaynes, D.B.; Cameron, S.C. Denitrifying bioreactors-an approach for reducing nitrate loads to receiving waters. Ecol. Eng. 2010, 36, 1532-1543. [CrossRef] 
18. Blowes, D.W.; Robertson, W.D.; Ptacek, C.J.; Merkley, C. Removal of agricultural nitrate from tile-drainage effluent water using in-line bioreactors. J. Contam. Hydrol. 1994, 15, 207-221. [CrossRef]

19. Goh, H.W.; Zakaria, N.A.; Lau, T.L.; Foo, K.Y.; Chang, C.K.; Leow, C.S. Mesocosm study of enhanced bioretention media in treating nutrient rich stormwater for mixed development area. Urban Water J. 2017, 14, 134-142. [CrossRef]

20. Geronimo, F.K.F.; Maniquiz-Redillas, M.C.; Kim, L.-H. Fate and removal of nutrients in bioretention systems. Desalt. Water Treat 2014, 53, 3072-3079. [CrossRef]

21. Li, W.W.; Yu, H.Q.; He, Z. Towards sustainable wastewater treatment by using microbial fuel cells-centered technologies. Energy Environ. Sci. 2014, 7, 911-924.

22. Razali, M.; Kim, J.F.; Attfield, M.; Budd, P.M.; Drioli, E.; Lee, Y.M.; Szekely, G. Sustainable wastewater treatment and recycling in membrane manufacturing. Green Chem. 2015, 17, 5196-5205. [CrossRef]

23. Kim, T.; Lee, J.; Lee, D.; Shin, H.; Kim, H.; Kwon, S. Verification of the Filter Media Applied to Filter Type Facility Considering the Treatment Efficiency Factor. J. Korean Soc. Water Environ. 2017, 33, 572-579.

24. Ministry of Environment (ME), Guideline Manual of Installation and Operation Management for Nonpoint Facility. 2014. Available online: https:/ / www.me.go.kr/home/web/policy_data/read.do?menuId=10259\& seq=4070 (accessed on 10 August 2018).

25. Hamoda, M.F.; Al-Ghusain, I.; AL-Mutairi, N.Z. Sand filtration of wastewater for tertiary treatment and water reuse. Desalination 2004, 164, 203-211. [CrossRef]

26. MWH. Water Treatment Principles and Design; John Wiley \& Sons, Inc.: Hoboken, NJ, USA, 2005; ISBN 978-0471110187.

27. Kim, S. Variation of Water Quality and Storm Runoff Impact in the Suyeong River. Ph.D. Thesis, Pukyong National University, Busan, Korea, August 2016.

28. McDowell, W.H.; Fisher, S.G. Autumnal processing of dissolved organic matter in a small woodland stream. Ecology 1976, 57, 561-569. [CrossRef]

29. Huber, S.A.; Huber, W.; Frimmel, F.H. Summarische Parameter für Organische Verbindungen; R. Oldenbourg: Munchen, Germany, 1993; pp. 47-67.

30. Tchobanoglous, G.; Burton, F.L.; Stensel, H.D. Wastewater Engineering Treatment and Reuse; McGraw-Hill Higher Education: Boston, MA, USA, 2003; ISBN 978-0070418783.

31. Oppenlöander, T. Photochemical Purification of Water and Air: Advanced Oxidation Processes; John Wiley \& Sons: Weinheim, Germany, 2007; ISBN 9783527305636.

32. Abdalla, K.Z.; Hammam, G. Correlation between biochemical oxygen demand and chemical oxygen demand for various wastewater treatment plants in Egypt to obtain the biodegradability indices. Int. J. Sci. Basic Appl. Res. 2014, 13, 42-48.

33. Ho, L.; Hoefel, D.; Bock, F.; Saint, C.P.; Newcombe, G. Biodegradation rates of 2-methylisoborneol (MIB) and geosmin through sand filters and in bioreactors. Chemosphere 2007, 66, 2210-2218. [CrossRef] [PubMed]

34. Davise, P.S. The Biological Basis of Wastewater Treatment; Strathkelvin Instruments LTD: Glasgow, UK, 2005; Available online: http://www.s-can.nl/media/1000154/thebiologicalbasisofwastewatertreatment.pdf (accessed on 11 July 2018).

35. Qualls, R.G.; Haines, B.L. Measuring adsorption isotherms using continuous, unsaturated flow through intact soil cores. Soil Sci. Soc. Am. J. 1992, 56, 456-460. [CrossRef]

36. Kalbitz, K.; Solinger, S.; Park, J.H.; Michalzik, B.; Matzner, E. Controls on the dynamics of dissolved organic matter in soils: A review. Soil Sci. 2000, 165, 277-304. [CrossRef]

37. Snoeyink, V.L.; Jenkins, D. Water Chemistry; Wiley: New York, NY, USA, 1980; ISBN 978-0471051961.

38. Wan, Z.; Li, T.; Shi, Z. A layered bioretention system for inhibiting nitrate and organic matters leaching. Ecol. Eng. 2017, 107, 233-238. [CrossRef]

39. Saad, R.; Belkacemi, K.; Hamoudi, S. Adsorption of phosphate and nitrate anions on ammonium-functionalized MCM-48: Effects of experimental conditions. J. Colloid Interface Sci. 2007, 311, 375-381. [CrossRef] [PubMed]

(C) 2018 by the authors. Licensee MDPI, Basel, Switzerland. This article is an open access article distributed under the terms and conditions of the Creative Commons Attribution (CC BY) license (http:/ / creativecommons.org/licenses/by/4.0/). 